\title{
Personal reflections on the menopause journey
}

\section{Abi Berger}

General Practitioner, London, UK

\section{Correspondence to}

Dr Abi Berger c/o journal@fsrh.org

Received 16 April 2016 Accepted 26 April 2016

\section{CrossMark}

To cite: Berger A. J Fam Plann Reprod Health Care 2016:42:225.
Magic happens in general practice. When I've got a particularly personal interest in an aspect of medicine, I seem to attract patients with similar issues. I like to think patients sniff me out in the aether - but of course it may simply be that I empathise more with those with similar issues - or that I'm more on the lookout for them.

For a while it was anxiety and the multiple ways this can manifest. Then it was visual disturbances which can be result from 'epiretinal membranes' - a diagnosis bestowed on me by an ophthalmologist I had consulted about flashing lights in my peripheral vision. The flashing lights had no connection with the membranes at the back of my eyes and settled eventually without intervention, but I am now familiar with the diagnosis.

I've recently embarked on the menopause journey. It started several months ago - my peripheral vision keeping me in a state of semi-denial - disturbed sleep, fairly gentle night sweats and eventually an acute plunge into a completely unexpected low mood. True to being a general practitioner (GP) I had put it all down to stress - until the mood swing.

The swing hit me with such a force and seemingly out of the blue - that when it switched off after 10 days and normal service was resumed on my 51st birthday - I began to consider other causes. The second time I was plunged into the abyss a few weeks later I made an appointment with my own GP. Not only were the mood swings terrible for me, but I could be found with my head in my hands between every patient I saw. I wasn't functioning very well.

The GP was quick to admit he didn't know much about estrogen as an adjunct to the intrauterine system. I knew I wanted to try a gel, so we dipped into the British National Formulary together and I came away with a prescription, and he now had something to write up for his annual appraisal.

The sweats stopped within 24 hours of applying the gel, my sleep improved and my mood stabilised happily. It has been 3 months. I am a convert to hormone replacement therapy (HRT). You won't find me throwing it at all my patients, but I like to think I'm getting better at identifying the women who might benefit from it.

Funnily enough it was a patient who had seen a psychiatrist last year who came to see me because she was hating the side effects of the antidepressant he'd prescribed, who really brought it home to me that fluctuating hormones might really be responsible for a lot of emotional anguish we women just kind of put up with. Within days of stopping the antidepressant and starting HRT she declared herself a new woman and hasn't looked back.

I'm also learning about dose responses. After liberally rubbing in a larger than usual squirt (I was still getting the hang of the canister), and then a much smaller squirt 24 hours later, I was plunged right back into depression and, unusually, fell asleep one Saturday afternoon. I applied logic and recalled what I'd given myself, and my theory for what it's worth is that I am exquisitely sensitive to the dose of estrogen and had inadvertently gone into withdrawal. I've been much more careful since.

So should I be concerned that I've introduced an obvious bias to my practice, on the basis of anecdote and a sample size of $n=1$ ? I don't think so. Reflected on with transparency, personal experience can contribute to the therapeutic exchange. And it is, after all, often present whether we acknowledge it or not.

Competing interests None declared.

Provenance and peer review Commissioned; internally peer reviewed. 